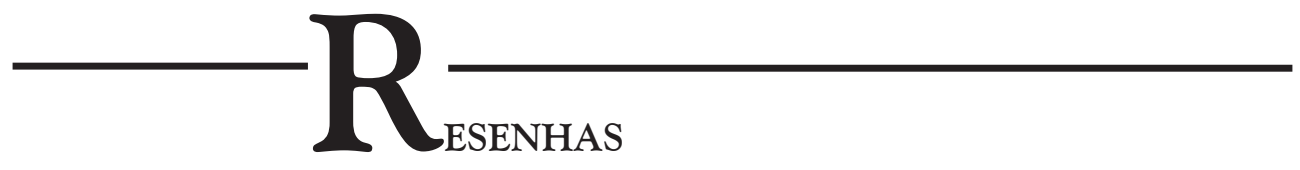

LABATE, Beatriz Caiuby; PACHECO, Gustavo. Música brasileira de Ayahuasca. Campinas: Editora Mercado das Letras, 2009, 120pp.

\title{
Música E AyahuASCA EM DUAS RELIGIÕES BRASILEIRAS
}

\section{Lucas Kastrup F. Rehen}

O Brasil é responsável pelo surgimento de diversas práticas religiosas e entre elas podemos encontrar as chamadas religiões ayahuasqueiras - dentre as quais se destacam: a doutrina do Santo Daime, a Barquinha e a União do Vegetal (UDV) -, assim denominadas por fazerem uso ritual de uma substância psicotrópica: ayahuasca ("cipó dos antepassado") ${ }^{1}$.

O consumo dessa infusão é largamente utilizado de diferentes maneiras pelos povos tradicionais da floresta amazônica e vem frequentemente acompanhado da execução e audição de cânticos, o que caracteriza sua utilização nos rituais das populações indígenas, entre os seringueiros amazônicos e também nessas três religiões, cada qual com suas especificidades musicais.

A música, nos variados rituais da ayahuasca, vem orientando, estimulando e oferecendo sentido às visões e demais efeitos proporcionados após a ingestão da bebida. O canto (e a música como um todo) é tido como inseparável da própria substância, 
entendido como parte fundamental da experiência: para os praticantes, os cânticos são obras da própria ayahuasca, agindo na materialização de curas e na transmissão de ensinamentos.

Ainda que a descoberta das religiões ayahuasqueiras pela perspectiva antropológica tenha se desenvolvido no início da década de 1980, quando desde os primeiros estudos esses rituais começaram a ser observados - e especialmente a doutrina do Santo Daime sendo definida como uma "religião musical" -, apenas duas décadas mais tarde, os hinos incessantemente entoados nas cerimônias passaram a receber maior atenção por parte de alguns pesquisadores ${ }^{2}$. No caso do Santo Daime, os primeiros autores, ainda sem um maior aprofundamento na questão musical já consideravam a centralidade dos cânticos, apontando a importância da quantidade de músicas que organizam o ritual, a participação dos frequentadores (seja cantando, dançando e/ou tocando instrumentos musicais) e o conteúdo das letras, mas evitavam o aprofundamento nessas discussões por uma questão de recorte e também por uma possível falta de formação musical. ${ }^{3}$

Recentemente, novas iniciativas intelectuais vêm sendo desenvolvidas nessa direção. Música brasileira de Ayahuasca, de Beatriz Caiuby Labate e Gustavo Pacheco ${ }^{4}$, é o primeiro livro publicado sobre o tema e investiga possíveis semelhanças e diferenças entre a experiência musical/ritual de duas religiões ayahuasqueiras: a doutrina do Santo Daime, com seus hinos, e a União do Vegetal (UDV), com as chamadas. Os trabalhos de Andrade (1979) ${ }^{5}$, Pacheco (1999) ${ }^{6}$, Abramowitz (2003) e Rehen (2007) ${ }^{7}$ são apresentados logo na introdução do livro como os "primeiros estudos acadêmicos voltados especificamente para a dimensão musical" (:18) sendo diversos dos pontos desenvolvidos por esses autores retomados ao longo do livro.

Labate e Pacheco abordam separadamente o contexto de surgimento de cada uma das religiões: o Santo Daime, desenvolvido no Acre pelo maranhense Raimundo Irineu Serra (mestre Irineu), por volta de 1930, e a União do Vegetal, fundada em Rondônia pelo baiano e também seringueiro José Gabriel da Costa (mestre Gabriel), em 1961. Citando que ambas teriam se expandido pelo Brasil e para outros países a partir dos anos 1980, os autores traçam um paralelo entre essas duas experiências religiosas, partindo do pressuposto de que teriam sido profundamente influenciadas por pelo menos três matrizes em comum: as tradições amazônicas, as diferentes vertentes do catolicismo popular brasileiro e as religiosidades afro-brasileiras. Cada uma dessas matrizes teria contribuído com seus elementos musicais e poéticos na construção dos gêneros musicais do Santo Daime e da UDV.

Para Labate e Pacheco, os hinos e as chamadas "podem ser considerados os portadores por excelência do corpus religioso das religiões ayahuasqueiras que estamos estudando" (:97). Essas músicas são entendidas por seguidores das duas religiões como mensagens enviadas do plano espiritual e nos dois casos devem ser propagadas mediante um ideal de manutenção da forma original apresentada nas letras e nas melodias.

Tanto os hinos do Santo Daime quanto as chamadas da União do Vegetal seriam herdeiros de uma tradição mais ampla de consumo da ayahuasca, nascida dos povos in- 
dígenas, mas também reinventada por parte dos seringueiros que ainda hoje consomem a bebida em reuniões muitas vezes informais, onde a música seria um meio de comunicação com seres invisíveis, trabalhando na produção de visões e também na cura. Para os autores, as chamadas da UDV com a execução individual, marcadas pelo não acompanhamento de instrumentos musicais e sem um repertório previamente definido, aproxima especialmente essa prática musical de outras tradições musicais ayahuasqueiras, como é o caso dos ícaros cantados entre os "vegetalistas" peruanos e estudados por Luna (1986) ${ }^{8}$.

Segundo Labate e Pacheco, algumas expressões presentes nos hinos do Santo Daime e nas chamadas da UDV podem ser também encontradas nos benditos (termo genericamente utilizado para designar as canções executadas em procissões católicas de várias regiões do país). Outros elementos formais dos benditos também apareceriam nos hinos e nas chamadas, como: a repetição de versos e estrofes, a repetição das últimas palavras de uma estrofe como primeiras palavras da próxima estrofe, a poesia narrativa e a presença de uma métrica recorrente, especialmente a quadra ou quadrinha (conjunto de quatro versos de sete sílabas poéticas, rimando o segundo com o quarto verso). Já alguns pontos de umbanda (cânticos da umbanda) teriam influenciado mais diretamente as chamadas da UDV, enquanto as tradições afro-brasileiras do Maranhão (tambor de crioula, bumba-meu-boi, entre outras) teriam influenciado os hinos do Santo Daime.

Entre as principais diferenças destacadas pelos autores está a "primazia da palavra", presente na UDV, onde as chamadas musicais (sempre individuais e entoadas apenas por alguém de considerável destaque na hierarquia interna) ocupam apenas uma parcela de tempo dentro do ritual. Este também conta com a exposição oral do mestre local, apresentando valores e normas de conduta da UDV por meio de palestras e leituras, havendo espaço para perguntas e respostas num diálogo entre os frequentadores e o líder. Além disso, algumas músicas, de variados gêneros musicais, são ouvidas por intermédio de aparelhos de som, dentro das sessões da UDV, levando-se em conta principalmente as poesias dessas canções que para serem selecionadas devem apresentar um vocabulário reconhecido pelo grupo como de cunho "positivo" e apropriado ao culto. Já no Santo Daime, além do silêncio e de algumas orações de abertura e de encerramento, o canto coletivo em uníssono - praticado por todos os adeptos (inclusive os visitantes) e acompanhado da dança (que aparece em rituais específicos) e por diversos instrumentos musicais - seria sua principal característica, compondo a maior parte dos chamados "trabalhos espirituais" onde as instruções e as narrativas são transmitidas basicamente por intermédio dos hinosde louvor, espiritualmente "recebidos" (como num tipo de psicografia musical) por líderes e poroutros seguidores da religião. No caso Santo Daime, o hinoé tido como a própria "voz da doutrina" (Rehen 2007).

Os autores afirmam que tanto na UDV quanto no Santo Daime as letras das músicas são consideradas importantes, mas alertam que esse fato não deve invalidar a riqueza da experiência individual proporcionada na vivência musical das religiões ayahuasqueiras, no contato com a bebida psicotrópica, onde muitas vezes o aspecto sonoro pode vir a transcender o conteúdo e a dimensão verbal. 


\section{Notas}

1 Esta tradução da palavra ayahuasca da língua quéchua pode ser encontrada em Luna, Luis Eduardo. (1986), Vegetalismo: Shamanism among The Mestizo Population of The Perwian Amazon. Stockholm: Almquist. Já o termo "religião ayahuasqueira" vem sendo adotado nos últimos anos por pesquisadores, por seguidores e pela mídia, como exposto por Labate em sua dissertação de mestrado A reinvenção do uso da ayahuasca nos centros urbanos, defendida em 2000 na Unicamp.

2 ABRAMOWITZ, Rodrigo Sebastian. (2003), Música e miração: uma análise etnomusicológica dos hinos do Santo Daime. Rio de Janeiro: Dissertação de Mestrado em Música Brasileira, UNIRIO.

3 Os hinos do Santo Daime, proporcionalmente opostos ao número de textos que o analisam diretamente, ocupam um lugar a que poucos elementos constitutivos desse ritual religioso poderiam se equiparar. Prova disso é a sua utilização, enquanto dados etnográficos, na justificação de argumentos teóricos variados. Encontramos poesias dos hinos sendo utilizadas em praticamente todas as pesquisas sobre o tema do Santo Daime, assim como partituras eventualmente colocadas no início ou final de algumas delas (Macrae, Edward. 1992, Guiado pela Lua: xamanismo e uso ritual da ayahuasca no culto do Santo Daime. São Paulo: Ed. Brasiliense). Sem que os hinos sejam analisados em sua dimensão propriamente musical, as notações musicais ilustram os trabalhos e testemunham mais uma vez a favor da centralidade dos cânticos nesse universo religioso.

4 Beatriz Labate e Gustavo Pacheco também escreveram um texto destacando aspectos fundamentais da relação entre a doutrina do Santo Daime e fenômenos culturais maranhenses, cf. Labate, Beatriz e Pacheco, Gustavo. (2004), "Matrizes maranhenses do Santo Daime”. In: B. C. Labate; W. S. Araújo (Orgs.). O uso ritual da ayahuasca. 2ed.Campinas: Mercado de Letras. Labate publicou em 2004 sua dissertação de mestrado, A reinvenção do uso da ayahuasca nos centros urbanos (Campinas: Mercado de Letras), em que analisou um grupo de São Paulo que estabelece novos códigos rituais em contexto urbano, quando cunhou o termo "neoayahuasqueiro". A autora também produziu duas coletâneas, uma delas sobre o uso ritual da ayahuasca e a outra sobre as plantas de poder, co-organizadas respectivamente por Labate e Araújo, O uso ritual da ayahuasca, em 2002 (Campinas: Mercado de Letras), e por Labate e Goulart, O uso ritual das plantas de poder, em 2005 (Campinas: Mercado de Letras).

5 ANDRADE, Julieta de. (1979), "Música e dança na 'miração' do Santo Daime”. MusicesAptatio Anuário de estudos hinológicos e musicológicos, s/n: 299-313.

6 PACHECO, Gustavo. (1999), Os hinos são as correntes: notas para um estudo antropológico da música no Santo Daime. Texto apresentado para a disciplina Antropologia da Religião, PPGAS/Museu Nacional/ UFRJ.

7 REHEN, Lucas Kastrup F. (2007), Recebido e ofertado: a natureza dos hinos na religião do Santo Daime. Rio de Janeiro: Dissertação de Mestrado em Ciências Sociais, PPCIS/UERJ.

8 LUNA, Luis Eduardo. (1986), Vegetalismo: Shamanism among The Mestizo Population of The Perwian Amazon. Stockholm: Almquist.

Lucas Kastrup F. Rehen (lkastrup@terra.com.br)

Doutor em Ciências Sociais pelo Programa de Pós-Graduação em Ciências Sociais da UERJ. 